\title{
2 POPULAR MATHEMATICS TITLES
}

\section{PEIRCE, FOSTER Short Table of Integrals, 4th Edition}

Classic text which includes additional definite integrals, further information on Bessel, and other transcendental functions. Expanded numerical tables.

\section{TAYLOR}

\section{Advanced Calculus}

Thorough treatment emphasizing concepts and basic principles of analysis-those properties of the real number system which support the theory of limits and continuify.

HOME OFFICE: Boston GIN N AND COMPANY

SALES OFFICES: NeW York 11

Dallas 1

Columbus 16

Chicago 6

Palo Alto

Atlanta 3

Toronto 7

\section{Recent}

\section{MEMOIRS OF THE AMERICAN MATHEMATICAL SOCIETY}

22. R. S. PALAIS, A global formulation of the Lie theory of transformation groups, 1957, iv, $123 \mathrm{pp}$.

23. D. G. Dickson, Expansions in series of solutions of linear difference-differential and infinite order differential equations with constant coefficients, $1957,72 \mathrm{pp}$.

24. IsAaC NAmioKa, Partially ordered linear topological spaces, 1957, 50 pp.

25. A. ERdélyi and C. A. Swanson, Asymptotic forms of Whittaker's confluent hypergeometric functions, 1957, 49 pp.

26. Walter Strodt, Principal solution of ordinary differential equations in the complex domain, 1957, $107 \mathrm{pp}$.

$25 \%$ discount to members

AMERICAN MATHEMATICAL SOCIETY 190 Hope Street, Providence, Rhode Island 


\section{PhD MATHEMATICIANS}

Our Systems Analysis Department has openiags for PhD Mathematicians who have a lasting interest in some fields of Mathematics such as Algebra, Geometry. Measure Theory. Topology. Differential Equations, Numerical Analysis, or Statistics. Association will be with others with similar educational background engaged in the study of challenging problems vital to the nation's welfare.

The work is of an independent research nature with a minimum of supervision by people of similar interests who are aware of the needs of research personnel.

Sandia Corporation, engaged in research and development of nuclear weapons, is located in Albuquerque, N.M.a metropolitan city of 208,000 famous for its splendid climate and its outstanding recreational and cultural attractions. Excellent working conditions and liberal employee benefits, including exceptionally generous paid vacations and holidays; retirement, hospital, and insurance plans.

\section{Announcing....}

A NEW expanded program for the translation and publication of four leading Russian physics journals. Published by the American Institute of Physics with the cooperation and support of the National Science Foundation.

Soviet Physics-Technical Physics. A translation of the "Journal of Technica Physics" of the Academy of Sciences of the U.S.S.R. 12 issues per year, approximately 4,000 Russian pages. Annually, $\$ 90.00$ domestic.

Soriet Phywics-Acoustics. A translation of the "Journal of Acoustics" of the Academy of Sciences of the U.S.S.R. Four issues per year, approximately 500 Russian pages. Annually, $\$ 20.00$ domestic. The 1955 issues of "Journal of Acoustics" U.S.S.R. will also be published. Will consist of two volumes, approximately 500 pages, and the subscription price will be $\$ 20.00$ for the set.
Soviet Physics-Doklady. A translation of the "Physics Section" of the Proceedings of the Academy of Sciences of the U.S.S.R. Six issues per year, approximately 900 Russian pages. Annually $\$ 25.00$ domestic.

Soriet Physics-JeTP. A translation of the "Journal of Experimental and Theoretical Physics" of the Academy of Sciences of the U.S.S.R. Twelve issues per year, approximately 2,600 Russian pages. Annually $\$ 60.00$ domestic. Back issues of Volume I and II are available.

All journals are to be complete translations of the 1956 issues of their Russian counterparts. The number of pages to be published represents the best estimate based on all available information now at hand.

Translated by competent, qualified scientists, the publications will provide all research laboratories and libraries with accurate and up-to-date information of the results of research in the U.S.S.R. Subscriptions should be addressed to the

\section{AMERICAN INSTITUTE OF PHYSICS}




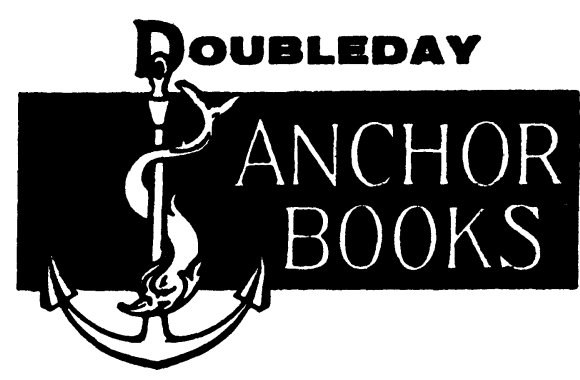

THREE

AHCHOR TITLES

\author{
E. $\mathcal{N}$. da C. \\ Andrade
}

AN APPROACH TO MODERN PHYSICS. One of the world's leading scientists presents the historical background and present status of contemporary physics. Anchor original.

95\%

$$
\text { G. Polya }
$$

HOW TO SOLVE IT. An outstanding mathematician shows how a unique approach to mathematics can be applied to solve problems in any other, more or less technical, area. $\quad 95 \phi$

\section{Tobias Dantzig}

NUMBER, THE LANGUAGE OF SCIENCE. A most informative, fascinating book on the evolution of the concept of number-from its beginnings among primitives, its development in the ancient world, and the many types of numbers used in higher mathematics today.

$95 \phi$

For a complete list, ask your bookseller or write to Doubleday Anchor Books, 575 Madison Avenue, New York 22.
CUSHING-MALLOY, INC.

Ann Arbor, Michigan

LITHOPRINTERS

Known for

QUALITY - ECONOMY

SERVICE

Let us quote on your next printing

\section{MEMOIRS 25 \\ ASYMPTOTIC FORMS OF WHITTAKER'S CONFLUENT HYPERGEOMETRIC FUNCTIONS by
A. ERDÉLYI and
C. A. Swanson

The principal results of the paper are uniform asymptotic forms for Whittaker's confluent hypergeometric functions $M_{k, m}$ - $(4 k x)$ and $W_{k, m}(4 k x)$ for unrestricted real values of $x$ when $k$ is large and $m \geq 0$. Two asymptotic forms for each function are obtained. Simplified asymptotic forms for restricted $x$-intervals are deduced from the main results.

$49 \mathrm{pp}$.

$\$ 1.40$

$25 \%$ discount to members
AMERICAN MATHEMATICAL SOCIETY
190 Hope Street
Providence, Rhode Island 


\section{American Mathematical Society}

\section{Bulletin of the American Mathematical Society}

This journal is the official organ of the Society. It reports official acts of the Society and the details of its meetings, with abstracts of all research papers presented. It contains some of the officially invited addresses presented before the Society, and reviews of advanced mathematical books.

The subscription price is $\$ 7.00$ per annual volume of six numbers.

Invited addresses offered for publication should be sent to B. J. Pertis, Department of Mathematics, Tulane University, New Orleans 18, La.; Research problems to G. B. PrICE, Department of Mathematics, University of Kansas, Lawrence, Kan.; Book reviews to J. C. OxтoBy, Bryn Mawr College, Bryn Mawr, Pa. All other communications to the editors should be addressed to the Managing Editor, G. B. PRICE.

\section{Proceedings of the American Mathematical Society}

This journal is devoted entirely to research in pure and applied mathematics and is devoted principally to the publication of original papers of moderate length.

The subscription price is $\$ 11.00$ per annual volume of six numbers.

Papers in algebra, number theory, logic and foundations should be sent to IRving KapLANSKY, Eckhart Hall, University of Chicago, Chicago, Ill.; in geometry and topology to HANS SAMELSON, Department of Mathematics, University of Michigan, Ann Arbor, Mich.; in probability, real variables and abstract analysis to SHrzuo KaKUTANI, Leet Oliver Memorial Hall, Yale University, New Haven 11, Conn.; in other branches of analysis, applied mathematics, and all other fields to R. P. BoAs, Lunt Building, Northwestern University, Evanston, Ill. All other communications to the editors should be addressed to the Managing Editor, IRVING KAPLANSKY.

\section{Transactions of the American Mathematical Society}

This journal is devoted entirely to research in pure and applied mathematics, and includes in general longer papers than the PROCEEDINGS.

Three volumes of two numbers each will be published in 1957. The subscription price is $\$ 8.00$ per volume.

Papers in geometry, differential equations and functions of complex variables should be sent to S. S. CHERN, Department of Mathematics, Massachusetts Institute of Technology, Cambridge 37, Mass.; in algebra and number theory to A. H. CLIFFORD, Newcomb College, Tulane University, New Orleans 18, La.; in analysis (except for differential equations and functions of a complex variable), applied mathematics and probability to Professor MARK KAC, White Hall, Cornell University, Ithaca, New York; in topology, logic and foundations to SAMUEL EILENBERG, Hamilton Hall, Columbia University, New York 27, N. Y. All other communications to the editors should be addressed to the Managing Editor, SAMUEL EILENBERG.

\section{Memoirs of the American Mathematical Society}

This series is devoted to the publication of research monographs in pure and applied mathematics. The memoirs are issued serially, but not periodically. Each issue consists of either a single monograph or a group of cognate papers and is priced separately according to size and cost of publication. The editorial standards for acceptance are the same as for the TRANSACTIONS and manuscripts intended for publication should be submitted to the appropriate editor of the TRANSACTIONS. All other communications to the editors should be addressed to S. S. CHERN.

\section{Mathematical Reviews}

This journal contains abstracts and reviews of the current mathematical literature of the world. It is sponsored by thirteen mathematical organizations, located both in the United States and abroad.

MATHEMATICAL Reviews is published monthly, excepting July. The subscription price is $\$ 35.00$ per annual volume of eleven numbers. 


\section{OFFICIAL COMMUNICATIONS}

\section{MeEtings of the Society}

Abstracts for all meetings of the Society should be sent to the American Mathematical Society, 190 Hope St., Providence 6, R. I.

Washington, D. C., October 26, 1957.

Abstracts must be received not later than September 12. By invitation of the Committee to Select Hour Speakers for Eastern Sectional Meetings there will be an address by Professor W. H. Gottschalk entitled Minimal sets: an introduction to topological dynamics.

Los Angeles, California, November 15-16, 1957.

Abstracts must be received not later than October 2. By invitation of the Committee to Select Hour Speakers for Far Western Sectional Meetings there will be an address by Professor Harold Levine entitled Recent developments in the theory of wave motion.

Coral Gables, Florida, November 29-30, 1957.

Abstracts must be received not later than October 2. By invitation of the Committee to Select Hour Speakers for Southeastern Sectional Meetings there will be an address by Professor A. H. Clifford.

Columbia, Missouri, November 29-30, 1957.

Abstracts must be received not later than October 2.

Annual Meeting, Cincinnati, Ohio, January 28-30, 1958.

Abstracts must be received not later than December 13.

J. W. Green, Secretary of the Society 